\title{
AN ULTIMATE STRENGTH DESIGN AID FOR FIXED-END STEEL ARCHES UNDER VERTICAL LOADS
}

\author{
By Tetsuya YABUKI*, Le-Wu LU** and Shigeru KURANISHI***
}

\begin{abstract}
To begin with, fixed-end restraint effects on the capacity of steel arches loaded into elastic or inelastic and finite deformation range is studied by a nonlinear finite element approach. Then, based on this result, a design formula which predicts the ultimate strength of fixed arches is proposed using effective length concept. By comparing with the analitically determined ultimate strength it is shown that these formulas accurately predict the strength of fixed arches for use in design.

Keywords : arch bridge, steel structure, compression member, structural stability, limit state design
\end{abstract}

\section{INTRODUCTION}

In conventional steel arch bridges, two-hinged supports might be chiefly provided because their erection was simpler than for arches with fixed-end supports. However, even in any practical arches, nonzero design bending moments result from live loads. Especially, for long span arches with slender ribs, their deflections become large. In these cases, fixed-ends should be desirable to minimize the amplification of initial geometrical imperfections and live load moments, and eventually to increase their ultimate strength. In arch structures, because of the presence of axial thrust, the ultimate strength is usually affected by instability and over-all failure occurs when the stability limit is reached ${ }^{1)-5)}$. This behavior is similar to the behavior of beam-columns or frames failing by instability, i. e., instability problems under combined axial compression and bending moment ${ }^{4}$.

For hinged arches, the design criterion formulated by the combined member forces is now available to determine their ultimate strength ${ }^{5)}$. However, for fixed arches, no rational procedure based on this instability concept has been developed. In this paper, first, the ultimate strength of fixed arches are discussed mainly in comparison with that of hinged arches. Then, a design aid is proposed, in which the fixed arch is transformed to become an equivalent hinged arch using the well-known effective length concept. Thus, it is possible to utilize directly the available design criteria for hinged arches and no instability analysis needs to be performed on the fixed arch. The proposed procedure is developed from the analytical results of an extensive study of the ultimate strength of fixed arches with a variety of structural and material parameters.

\footnotetext{
* Member of JSCE, Dr. Eng., Associate Professor, Department of Civil Engineering, University of Ryukyu (Okinawa)

** Ph. D., Professor, Department of Civil Engineering, Lehigh University (Bethlehem, Pa., U. S. A.)

*** Member of JSCE, Dr. Eng., Professor, Department of Civil Engineering, Tohoku University (Sendai)
} 


\section{GENERALITIES}

\section{(1) Description of Analysis and Arch Studied}

A nonlinear finite element analysis has been developed to study the ultimate strength of arches ${ }^{3), 5)}$ and the same approach is used in this study. It is assumed that no out-of-plane deformation occurs anywhere in the structure and that the strength is governed by instability failure in the vertical plane. Two types of instability analysis have been performed, one is the elastic analysis and the other the inelastic analysis, both including the effect of finite deformation. The inelastic analysis takes into account spread of yielding, unloading and reloading of the yielded parts in the cross section and along the length, and residual stress due to welding. The load versus deformation relationship of the arch is obtained by successively incrementing the load until the maximum value is reached. For each load increment the tangent stiffness method and the Newton-Raphson iterative procedure are used ${ }^{7}$. The component plates of the cross section are assumed not to fail prematurely by local buckling.

The arch selected for the study is the same as used in Refs 3), 5) and has a perfectly parabolic axial configuration with a span length $L$ and a rise $h$ as shown in Fig. 1. The structure has a uniform cross section and is constructed of thin-walled welded box section. The arch is loaded by a series of concentrated loads at the nodal points which have been pre-selected for the finite element analysis ${ }^{3}$. The load acting at each nodal point on the left half of the arch is $q$ and that on right half is $r q$, where $r$ is a load reduction factor. The load $q$ represents combined dead, live, and impact loads, while $r q$ represents dead load only. In all the numerical calculations, the arch is divided into 20 segments with equal length along the span and nodal point runs from 1 to 21 . The loads at points 1 and $n(=21)$ are assumed to be transmitted directly to the supports and therefore produce no effect on the arch. By dividing the cross section into 40 segments the elements of tangent stiffness matrix are evaluated numerically. These discrete treatment manners are the same as those used in the previous studies of hinged arches ${ }^{5)}$ and fixed arches ${ }^{3)}$.

For comparison purpose, the cross sectional properties of the box section and the magnitude and distribution of residual stresses assumed in the numerical calculations are also the same as those used in the Refs. 3$)$ and 5), as shown in Fig. 1 ( $H, B=$ depth and width of the cross section; $t_{f}, t_{w}=$ thickness of a flange and a web plate; $A_{f}, A_{w}=$ sectional area of a flange and a web plate; $r_{x}=$ radius of gyration, and $k$ $=$ core radius). The pattern of residual stress is taken from Ref. 6) originally, and has a maximum stress at the welds equal to the yield stress of material and the maximum stress in compression equal to $40 \%$ of the yield stress. The structural parameters in the study are the rise-to-span ratio $h / L$, the slenderness ratio $\lambda$ which is the ratio of the curvilinear length of the arch axis, $L_{s}$, to the radius of gyration of the cross section, $r_{x}$, the load reduction factor $r$, and the yield stress of material $\sigma_{y}$. The ranges of these
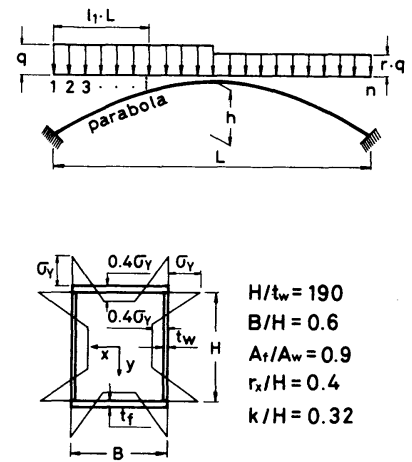

$H / t_{w}=190$

$B / H=0.6$

$A_{t} / A_{w}=0.9$

$r_{x} / H=0.4$

$k / H=0.32$

Fig. 1 Fixed-End Arch and Its Cross Section Studied.

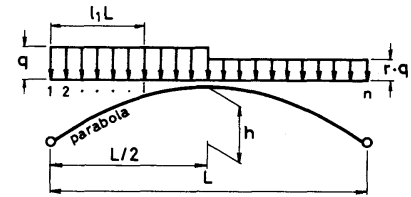

(a) replaced hinged arch

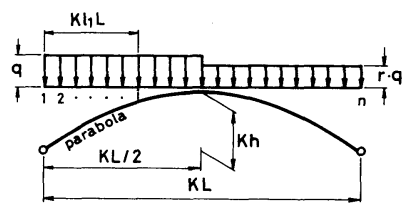

(b) equivalent hinged arch

Fig. 2 Replaced Hinged Arch and Equivalent Hinged Arch. 
parameters selected as given below are generally within those found in steel arch bridges:

$h / L=0.1 \sim 0.3 ; \lambda=100 \sim 300 ; r=0 \sim 0.99 ; \sigma_{y}=240 \sim 460 \mathrm{~N} / \mathrm{mm}^{2}$

The Young's modulus $E$ is kept constant at $2.1 \times 10^{5} \mathrm{~N} / \mathrm{mm}^{2}$.

\section{( 2 ) Principal Effects of End Restraint}

Some typical results of the study are shown in Fig. 3, where the load-deflection relationships at a quarter point of an arch with $h / L=0.15, \lambda=200$ and $\sigma_{y}=320 \mathrm{~N} / \mathrm{mm}^{2}$. The $r$ values are $0,0.5,0.75$ and 0.99 , respectively. The load $q$ is nondimensionalized with respect to a reference load $q_{p}$. This load, when applied at all the nodal points ( 2 through 20 ), will cause full yielding at the springing under axial thrust. It is given by :

$$
q_{p}=\frac{A_{a} \sigma_{y}}{\sqrt{\left[\frac{n-2}{2}\right]^{2}+\left[\sum_{i=1}^{n} \frac{5 L}{8 h} l_{1} l_{2}\left(l_{1}^{2}+3 l_{1} l_{2}+l_{2}^{2}\right)\right]^{2}}}
$$

in which $n=$ number of nodes, $l_{1}=(i-1) /(n-1), l_{2}=l-l_{1}, i=$ order of nodal point (Fig. 1), and $A_{a}=$ cross sectional area of arch. $q_{p}$ depends on the $h / L$ ratio, $A_{a}$ and $\sigma_{y}$, and is the same for hinged or fixed arch. The results of the elastic instability analysis are shown as the dashed curves in Fig. 3 and those of the inelastic analysis are given by the solid curves. The elastic analysis shows that for $r=0.99$ the maximum load $q_{\text {max,elast }}$ is almost equal to the linear bifurcation buckling load $q_{\text {buckle }}$ and that $q_{\text {max,elast }}$ dose not change with the value of $r$ very much. The true maximum load carrying capacity, i. e., the ultimate strength, is the maximum load $q_{\max }$ of the inelastic analysis, which is generally much lower than the elastic value $q_{\text {max,elast. }}$. Also, $q_{\max }$ decreases significantly as the applied load becomes more unsymmetrical. The load at which initial yielding occurs in the structure (residual stress effect not considered) determined by the second-order elastic analysis is shown as the elastic limit load $q_{y, 2 n d}$ in Fig. 3 .

In Table 1 , these loads $q_{\max }, q_{\text {max,elast }}$, and $q_{y, 2 n d}$ are summarized. The elastic limit load calculated by the conventional first-order elastic analysis $q_{y, 1 \text { st }}$ is also tabulated. The $q_{\max }$ and $q_{y, 2 \text { nd }}$ values obtained can be used to study the margin of safety of the arch if it is designed by the allowable stress method using the results of a second-order elastic analysis. For the case $r=0$, if a factor of safety 1.67 against yielding is used in establishing the allowable stress, the margin of safety against instability failure is $1.67 \mathrm{X}$ $0.340 / 0.228=2.49$. For $r=0.5$ the margin is 2.26 and for $r=0.99$ this value is 1.59 . If the elastic limit loads are calculated by the convensional first-order elastic analysis, the corresponding margins of safety become $2.41,2.01$ and 1.38 . The last figure for either the first- or second-order analysis is certainly lower than the safety margins specified in most of the bridge specifications ${ }^{8), 9)}$. Actually, an allowable stress less than $\sigma_{y} / 1.67=0.6 \sigma_{y}$ is often used in practice to account for the effect of instability. A rational design procedure based directly on the ultimate strength is needed in order to achive an adequate and consistent safety margin in design.

Some selected results of analysis for the ultimate strength of fixed arches for the ranges of $h / L, \lambda$ and $r$ described before are given in Table 2, where they are compared with the results of hinged arches having identical, geometrical and material properties and loading conditions as shown in Fig. 2 (a) (termed as

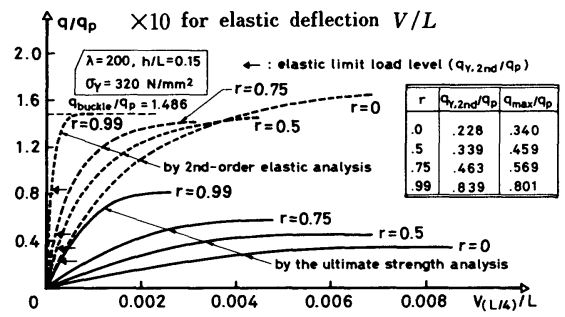

Table 1 Ultimate Strength of Fixed Arches Compared. with Critical Loads Obtained by Elastic Analysis.

\begin{tabular}{l|c|c|c|c}
\hline $\mathbf{r}$ & $\begin{array}{c}\mathrm{q}_{\max } / \mathrm{q}_{\mathrm{p}} \\
(2)\end{array}$ & $\begin{array}{c}\mathrm{q}_{\max , \mathrm{elast}} / \mathrm{q}_{\mathrm{p}} \\
(1)\end{array}$ & $\begin{array}{c}\mathrm{q}_{\mathrm{y}, 2 \mathrm{2nd}} / \mathrm{q}_{\mathrm{p}} \\
(4)\end{array}$ & $\begin{array}{c}\mathrm{q}_{\mathrm{y}, 1 \mathrm{st}} / \mathrm{q}_{\mathrm{p}} \\
(5)\end{array}$ \\
\hline 0 & 0.340 & 1.637 & 0.228 & 0.236 \\
0.5 & 0.459 & 1.439 & 0.339 & 0.381 \\
0.75 & 0.569 & 1.413 & 0.463 & 0.515 \\
0.99 & 0.801 & 1.480 & 0.839 & 0.969 \\
\hline Note $: \lambda=200, \mathrm{~h} / \mathrm{L}=0.15, \sigma_{\mathrm{y}}=320 \mathrm{~N} / \mathrm{mm}^{2}$ \\
\hline
\end{tabular}

Fig. 3 Load-Deflection Curves at Quarter Point of Fixed Arch. 
Table 2 Ultimate Strength of Fixed Arches Compared with Those of Two-Hinged Arches (for various of $r$, $h / L$ and $\lambda)$.

\begin{tabular}{|c|c|c|c|c|c|c|c|}
\hline \multirow{2}{*}{$\mathbf{r}$} & \multirow{2}{*}{$\begin{array}{c}\text { Arch Type } \\
\text { and } \\
\text { ratio of increase }\end{array}$} & \multicolumn{3}{|c|}{$\lambda=200$} & \multicolumn{3}{|c|}{$h / \mathrm{L}=0.15$} \\
\hline & & $\mathrm{h} / \mathrm{L}=0.1$ & $h / L=0.15$ & $h / L=0.3$ & $\lambda=100$ & $\lambda=200$ & $\lambda=300$ \\
\hline \multirow[t]{3}{*}{0} & fixed-ends & 0.400 & 0.340 & 0.303 & 0.672 & 0.340 & 0.207 \\
\hline & hinged-ends & 0.262 & 0.213 & 0.174 & 0.467 & 0.213 & 0.125 \\
\hline & ratio of increase & 0.527 & 0.596 & 0.741 & 0.439 & 0.596 & 0.656 \\
\hline \multirow[t]{3}{*}{0.5} & fixed-ends & 0.496 & 0.459 & 0.454 & 0.795 & 0.459 & 0.283 \\
\hline & hinged-ends & 0.321 & 0.288 & 0.259 & 0.607 & 0.288 & 0.159 \\
\hline & ratio of increase & 0.545 & 0.594 & 0.753 & 0.310 & 0.594 & 0.780 \\
\hline \multirow[t]{3}{*}{0.99} & fixed-ends & 0.731 & 0.801 & 0.956 & 0.961 & 0.801 & 0.555 \\
\hline & hinged-ends & 0.521 & 0.538 & 0.580 & 0.837 & 0.538 & 0.280 \\
\hline & ratio of increase & 0.403 & 0.489 & 0.648 & 0.148 & 0.489 & 0.982 \\
\hline
\end{tabular}

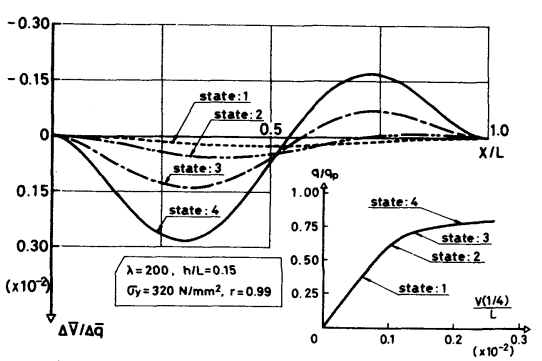

Fig. 4 Incremental Vertical Deflection Mode at Each Loading State (for $r=0.99$ ).

"replaced hinged arch"). From this table it is obvious that the ultimate strength of the fixed arches decreases significantly as the applied load becomes more unsymmetrical and as the slenderness ratio increases. The ultimate strength for $r=0$ and $r=0.5$ also decreases with increasing the rise-to-span ratio. For $r=0.99$, however, it increases with the rise-to-span ratio because of influence of buckling phenomenon ${ }^{3)}$. The basic trend observed also holds for the hinged arches. The increase in strength of a fixed arch over a hinged arch is measured by the ratio $\left(q_{\max }^{f}-q_{\max }^{h}\right) / q_{\max }^{h}$, where $q_{\max }^{f}$ and $q_{\max }^{h}$ are respectively the calculated ultimate strength of the fixed and hinged arches. This ratio is also shown in Table 2 as a "ratio of increase". The data indicate that this ratio becomes larger as the slenderness ratio or the rise-to-span ratio or both becomes larger.

Fig. 4 shows typical nondimensional forms of incremental vertical deflections along a fixed arch span $(\lambda$ $=200$ ) -incremental deflection mode - from low level loading state to the ultimate state for $r=0.99$, where the mode is given by dividing the nondimensional incremental deflection $(\Delta \bar{v}=\Delta v / L)$ by the dimensionless load intensity $\left(\Delta \bar{q}=\Delta q / q_{p}\right)$. From the figure the incremental deflection mode for low level loadings is seen to be the first order mode in which a shortening deformation is distinguished, while when the axial thrust becomes relatively higher the deflection mode changes to the bending deformation mode (second order mode). Thus, the so-called inelastic buckling phenomenon appears in this case. It could be understood that the bending deflection mode becomes eventually dominant at the ultimate states even in the quasi-symmetrical loading case.

The effect of fixed-end restraint on the behavior of the arches has been previously studied in Ref. 3) in detail from qualitative point of view. From the previous and present studies, it has been found that in the inelastic range the bending deformation tends to increase more repidly than the axial deformation and that fixed-end restraint remains effective until the ultimate load is reached.

\section{DESIGN AID}

\section{(1) Effective Length Concept}

The extensive numerical results obtained from the study make the development of an ultimate strength design procedure in fixed arches. This procedure permits direct use of the design criteria that have been proposed previously for hinged arches ${ }^{5}$. The first step is to establish an equivalent hinged arch which would have the same ultimate strength as the fixed arch. The analytical study of fixed arch shows that the increase in strength is due primarily to the rotational restraining effect at the springing. This effect, of course, is also present in analyzing fixed arches for their bifurcation buckling. A simple way of recognizing the restraint effect is to use the "effective length concept", in which the buckling strength of the fixed arch is related to that of an equivalent hinged arch with a reduced rib axis length (shown in Fig. 2 (b)). The two arches (Fig. 1 and Fig. 2 (a)) have identical, cross sectional dimensions, material properties, rise-to-span ratio and load reduction factor. Fig. 5 shows the relationship between the effective length factor $K$ and the rise-to-span ratio $h / L$ for fixed arches based on the linear buckling 


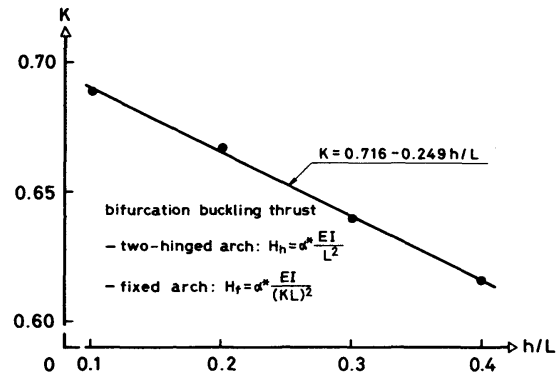

Fig. 5 Effective Length Factor of Fixed Arch.

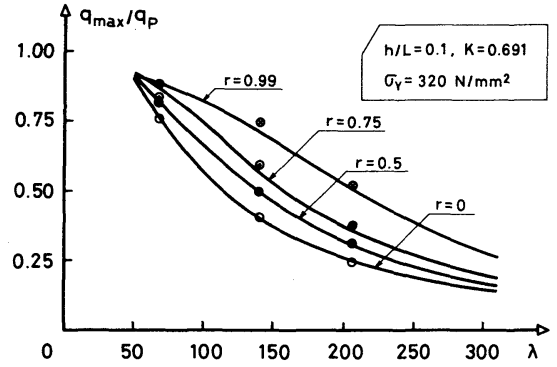

Fig. 6 Strength Comparison of Fixed Arch and Equivalent Hinged Arch (for $h / L=0.1$ ).

analysis. By applying a regression analysis on statistics a prediction formula for $K$ can be obtained as follows :

$$
K=0.716-0.249 h / L
$$

This formula is also shown in Fig. 5.

It is proposed to use the same $K$ value to define the equivalent arch for evaluating the ultimate strength of fixed arches. The equivalent arch is loaded in the same manner as the fixed arch. The accuracy of using the equivalent arch defined by Eq. (2) in evaluating the strength of fixed arches is illustrated in Fig. 6. The solid curves show the ultimate load $q_{\max } / q_{p}$ of hinged arches with $h / L=0.1$ and $\sigma_{y}=320 \mathrm{~N} / \mathrm{mm}^{2}$ as a function of $\lambda$ for $r$ values of $0,0.5,0.75$ and 0.99 . For comparison purpose the $q_{\max } / q_{p}$ values calculated for fixed arches with $\lambda=100,200$ and 300 are plotted at the equivalent slenderness ratio of $K \lambda=69.1$, 138.2 and 207.3, respectively, in which $K=0.716-0.249 \times 0.1=0.691$. These ultimate loads are indicated by the circular marks. Same comparisons for $h / L=0.15$ and 0.3 are also shown in Figs 7 and 8 . The correlations are considered satisfactory. Similar studies for arches with different yield stress also show reasonable correlations. It may be concluded that the equivalent arch concept proposed herein gives results which are sufficiently accurate for practical applications.

\section{(2) Ultimate Strength Design Formulas}

The second step is to establish ultimate strength formulas being applicable to the equivalent hinged arch. The criteria proposed previously for hinged arches are expressed in terms of the axial thrust $N$ and bending moment $M$ at the critical quarter point determined from a first-order elastic analysis at the design ultimate load (working load multiplied by a factor). They are as follows 5 ) :

$$
\begin{aligned}
& a\left[\frac{M}{M_{y}}\right]^{2}+b\left[\frac{M}{M_{y}}\right]+c\left[\frac{N}{N_{y}}\right] \leqq 1.0 \text { for } \frac{N}{N_{y}} \geqq n_{c r} \\
& \alpha\left[\frac{M}{M_{y}}\right]+\beta\left[\frac{N}{N_{y}}\right] \leqq 1.0 \text { for } \frac{N}{N_{y}}<n_{c r} \ldots \ldots \ldots \ldots \ldots . . .
\end{aligned}
$$

in which $a, b, c, \alpha$ and $\beta$ are empirical coefficients and $n_{c r}$ is a nondimensional axial load. These

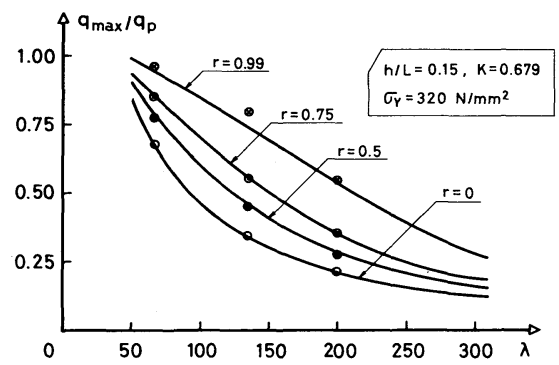

Fig. 7 Strength Comparison of Fixed Arch and Equivalent Hinged Arch (for $h / L=0.15$ ).

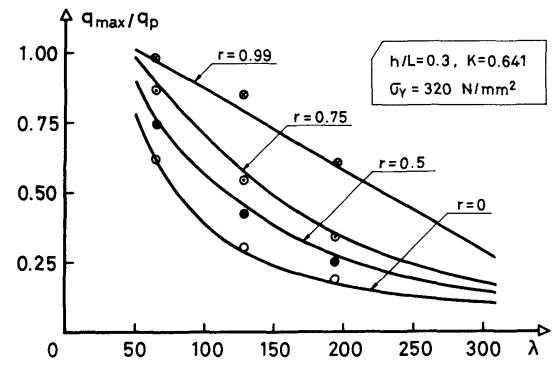

Fig. 8 Strength Comparison of Fixed Arch and Equivalent Hinged Arch (for $h / L=0.3$ ). 
coefficients and $n_{c r}$ are depending on rise-to-span ratio, $h / L$, and slenderness ratio parameter

$$
\bar{\lambda}=\lambda \sqrt{\sigma_{y} / E} / \pi
$$

Namely :

$$
\begin{aligned}
& a=2.509-1.689 \bar{\lambda} ; b=-1.213+1.605 \bar{\lambda}-0.135 \bar{\lambda}^{2} ; c=\left(1.824-0.914 \bar{\lambda}+0.376 \bar{\lambda}^{2}\right)(0.82+1.2 h / L) ; \\
& \alpha=1 / m_{p} ; \beta=\left(m_{p}-m_{c r}\right) /\left(m_{p} n_{c r}\right) ; m_{p}=1.172-0.0469 \bar{\lambda} ; n_{c r}=\left(1-b m_{c r}-a m_{c r}^{2}\right) / c ; \\
& m_{c r}=m_{p} \text { for }\left(a m_{p}^{2}+b m_{p}-1\right) / a \leqq 0 ; m_{c r}=m_{p}-\sqrt{\left(a m_{p}^{2}+b m_{p}-1\right) / a} \text { for }\left(a m_{p}^{2}+b m_{p}-1\right) / a>0 .
\end{aligned}
$$

In the following discussion the superscript ${ }^{\wedge}$ will be used to indicate structural properties associated with the equivalent arch, thus :

$$
\begin{aligned}
& \hat{L}=K L ; \hat{h}=K h ; \hat{\lambda}=K \lambda . \\
& \hat{q}_{\max }=q_{\max }^{f} \cdots \cdots \cdots \cdots \cdots \cdots
\end{aligned}
$$

The equivalent arch is analyzed by a first-order elastic analysis at its ultimate load $q_{\max }=q_{\max }^{f}$ and the resulting axial thrust and bending moment at the critical quarter point are :

$$
\hat{N}=k_{n} q_{\max }^{f} ; \hat{M} /(K L)=k_{m} q_{\max }^{f}
$$

in which $k_{n}$ and $k_{m}$ are constants for a given $h / L$ ratio and $r$ value. Next consider the replaced hinged arch, which is the same as the fixed arch in all respects except that the supports are hinged. To this arch the design criteria given by Eqs. (3.1), (3.2) and (3.3) are directly applicable. The superscript will be used when refering to the properties of the replaced arch. The axial thrust and bending moment at the same quarter point of this arch at its ultimate load

$\tilde{q}_{\max }=q_{\max }^{h}$ are :

$$
\tilde{N}=k_{n} q_{\max }^{h} ; \tilde{M} / L=k_{m} q_{\max }^{h}
$$

From Eqs. ( 5 ) and (6):

$$
\hat{N}=\tilde{N} q_{\max }^{f} / q_{\max }^{h} ; \hat{M}=K \tilde{M} q_{\max }^{f} / q_{\max }^{h}
$$

or expressing nondimensionally :

$$
\frac{\hat{N}}{N_{y}}=\frac{\tilde{N}}{N_{y}} \frac{q_{\max }^{f} / q_{p}}{q_{\max }^{h} / q_{p}} ; \frac{\hat{M}}{M_{y}}=K \frac{\tilde{M}}{M_{y}} \frac{q_{\max }^{f} / q_{p}}{q_{\max }^{h} / q_{p}}
$$

in which $N_{y}$ is the yield axial thrust and $M_{y}$ the yield bending moment of the arch cross section. They are the same for the fixed arch, the equivalent hinged arch and the replaced hinged arch.

Eq. (8) can be rewritten as:

$$
\hat{n}=\tilde{n} \hat{f} / \tilde{f} ; \hat{m}=K \tilde{m} \hat{f} / \tilde{f}
$$

in which $\hat{n}=\hat{N} / N_{y}, \tilde{n}=\tilde{N} / N_{y}, \hat{m}=\hat{M} / M_{y}, \tilde{m}=\tilde{M} / M_{y}, \hat{f}=q_{\max }^{f} / q_{\rho}, \tilde{f}=q_{\max }^{h} / q_{\rho}$. Fig. 9 shows how the design criterion for the replaced arch can be transformed to become the criterion for the equivalent arch based on Eq. (9). The lower curve shows the criterion for the replaced arch and each point on the curve represents a critical combination of $\tilde{n}$ and $\tilde{m}$ at the ultimate state, for instance, point $\mathrm{A}$. The $\tilde{n}$ and $\tilde{m}$ are then multiplied by $\hat{f} / \tilde{f}$ to obtain $\bar{n}$ and $\bar{m}$ (point B). Thus :

$$
\bar{n}=\tilde{n} \hat{f} / \tilde{f} ; \bar{m}=\tilde{m} \hat{f} / \tilde{f}
$$

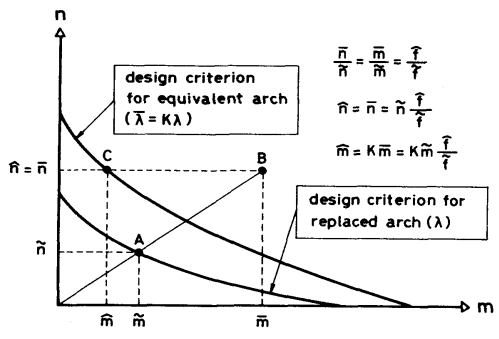

Fig. 9 Transformation of Design Criteria.

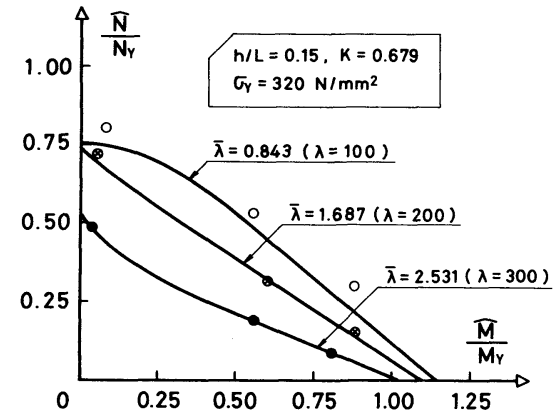

Fig. 10 Comparison of Calculated Strength with Predicted Strength Based on Proposed Criteria. 
Table 3 Comparison of Analytically Calculated Ultimate Strength with Predicted Strength (for various values of $r$ and $\lambda$ ).

\begin{tabular}{|c|c|c|c|c|c|c|}
\hline $\begin{array}{c}\mathbf{r} \\
(1)\end{array}$ & $\begin{array}{l}(\lambda) \\
\bar{\lambda} \\
(2)\end{array}$ & $\begin{array}{l}\hat{f} \\
\text { (3) }\end{array}$ & $\begin{array}{l}\hat{f} / \tilde{f} \\
(4)\end{array}$ & $\begin{array}{l}\tilde{\mathrm{Km}} \cdot(4) \\
(5)\end{array}$ & $\begin{array}{c}\tilde{n} \cdot(4) \\
(6)\end{array}$ & $\begin{array}{l}F_{C} \\
\text { (7) }\end{array}$ \\
\hline 0 & $\begin{array}{l}(100) \\
0.843 \\
(200) \\
1.687 \\
(300) \\
2.531\end{array}$ & $\begin{array}{l}0.672 \\
0.340 \\
0.207\end{array}$ & $\begin{array}{l}1.439 \\
1.596 \\
1.656\end{array}$ & $\begin{array}{l}0.883 \\
0.878 \\
0.797\end{array}$ & $\begin{array}{l}0.305 \\
0.152 \\
0.092\end{array}$ & $\begin{array}{l}1.098 \\
1.017 \\
0.983\end{array}$ \\
\hline 0.5 & $\begin{array}{l}(100) \\
0.843 \\
(200) \\
1.687 \\
(300) \\
2.531\end{array}$ & $\begin{array}{l}0.795 \\
0.459 \\
0.283\end{array}$ & $\begin{array}{l}1.310 \\
1.594 \\
1.780\end{array}$ & $\begin{array}{l}0.559 \\
0.604 \\
0.553\end{array}$ & $\begin{array}{l}0.533 \\
0.308 \\
0.190\end{array}$ & $\begin{array}{l}1.051 \\
0.986 \\
0.993\end{array}$ \\
\hline 0.99 & $\begin{array}{l}(100) \\
0.843 \\
(200) \\
1.687 \\
(300) \\
2.531\end{array}$ & $\begin{array}{l}0.961 \\
0.801 \\
0.555\end{array}$ & $\begin{array}{l}1.148 \\
1.489 \\
1.982\end{array}$ & $\begin{array}{l}0.082 \\
0.050 \\
0.035\end{array}$ & $\begin{array}{l}0.855 \\
0.713 \\
0.494\end{array}$ & $\begin{array}{l}1.139 \\
1.018 \\
1.015\end{array}$ \\
\hline
\end{tabular}

For the equivalent arch the design criterion is defined according to Eq. (9) by:

$$
\hat{n}=\bar{n} ; \hat{m}=K \bar{m}
$$

This is shown as point $C$ on the upper curve. The upper curve can be obtained directly by applying Eqs. (3.1), (3.2) and (3.3) to the equivalent arch as follows :

$$
\begin{aligned}
& a \hat{m}^{2}+b \hat{m}+c \hat{n} \leqq 1.0 \text { for } \hat{n} \geqq n_{c r} \cdots \cdots \cdots \cdots(12.1) \\
& \alpha \hat{m}+\beta \hat{n} \leqq 1.0 \text { for } \hat{n}<n_{c r} \cdots \cdots \cdots \cdots \cdots \cdots(12.2) \\
& \bar{\lambda}=K \lambda \sqrt{\sigma_{y} / E} / \pi=(0.716-0.249 h / L) \lambda \sqrt{\sigma_{y} / E} / \pi
\end{aligned}
$$

\begin{tabular}{|c|c|c|c|c|c|c|}
\hline $\begin{array}{c}\mathrm{r} \\
\text { (1) }\end{array}$ & $\begin{array}{l}h / L \\
(2)\end{array}$ & $\begin{array}{c}\hat{f} \\
(3)\end{array}$ & $\begin{array}{l}\hat{f} / \tilde{f} \\
(4)\end{array}$ & $\begin{array}{l}\tilde{\mathrm{Km}} \cdot(4) \\
(5)\end{array}$ & $\begin{array}{c}n \cdot(4) \\
(6)\end{array}$ & $\begin{array}{r}F_{\mathrm{C}} \\
(7)\end{array}$ \\
\hline \multirow[t]{3}{*}{0} & 0.1 & 0.400 & 1.527 & 0.791 & 0.189 & 0.979 \\
\hline & 0.15 & 0.340 & 1.596 & 0.878 & 0.152 & 1.017 \\
\hline & 0.3 & 0.303 & 1.741 & 0.964 & 0.113 & 1.058 \\
\hline \multirow[t]{3}{*}{0.5} & 0.1 & 0.496 & 1.545 & 0.507 & 0.352 & 0.937 \\
\hline & 0.15 & 0.459 & 1.594 & 0.604 & 0.308 & 0.986 \\
\hline & 0.3 & 0.454 & 1.753 & 0.730 & 0.254 & 1.068 \\
\hline \multirow[t]{3}{*}{0.99} & 0.1 & 0.731 & 1.403 & 0.057 & 0.688 & 0.945 \\
\hline & 0.15 & 0.801 & 1.489 & 0.050 & 0.713 & 1.018 \\
\hline & 0.3 & 0.956 & 1.648 & 0.045 & 0.710 & 1.152 \\
\hline
\end{tabular}

Table 4 Comparison of Analytically Calculated Ultimate Strength with Predicted Strength (for various values of $r$ and $h / L$ ).

\begin{tabular}{|c|c|c|c|c|c|c|}
\hline $\begin{array}{c}\mathbf{r} \\
\text { (1) }\end{array}$ & $\begin{array}{c}\left(\sigma_{\mathrm{y}}^{\left.\mathrm{N} / \mathrm{mm}^{2}\right)}\right. \\
\bar{\lambda} \\
(2)\end{array}$ & $\begin{array}{c}\hat{f} \\
(3)\end{array}$ & $\begin{array}{l}\hat{\mathrm{f}} / \tilde{\mathrm{f}} \\
(4)\end{array}$ & $\begin{array}{c}\tilde{\mathrm{Km}} \cdot(4) \\
(5)\end{array}$ & $\begin{array}{c}n \cdot(4) \\
(6)\end{array}$ & $\begin{array}{r}F_{c} \\
(7) \\
\end{array}$ \\
\hline 0 & $\begin{array}{l}(240) \\
1.460 \\
(320) \\
1.687 \\
(460) \\
2.022\end{array}$ & $\begin{array}{l}0.359 \\
0.340 \\
0.313\end{array}$ & $\begin{array}{l}1.541 \\
1.596 \\
1.598\end{array}$ & $\begin{array}{l}0.928 \\
0.878 \\
0.810\end{array}$ & $\begin{array}{l}0.161 \\
0.152 \\
0.140\end{array}$ & $\begin{array}{l}1.026 \\
1.017 \\
0.993\end{array}$ \\
\hline 0.5 & $\begin{array}{l}(240) \\
1.460 \\
(320) \\
1.687 \\
(460) \\
2.022\end{array}$ & $\begin{array}{l}0.496 \\
0.459 \\
0.409 \\
\end{array}$ & $\begin{array}{l}1.503 \\
1.594 \\
1.657 \\
\end{array}$ & $\begin{array}{l}0.654 \\
0.604 \\
0.539 \\
\end{array}$ & $\begin{array}{l}0.333 \\
0.308 \\
0.275 \\
\end{array}$ & $\begin{array}{l}0.999 \\
0.986 \\
0.973\end{array}$ \\
\hline 0.99 & $\begin{array}{l}(240) \\
1.460 \\
(320) \\
1.687 \\
(460) \\
2.022 \\
\end{array}$ & $\begin{array}{l}0.864 \\
0.801 \\
0.699\end{array}$ & $\begin{array}{l}1.307 \\
1.487 \\
1.561\end{array}$ & $\begin{array}{l}0.054 \\
0.050 \\
0.043 \\
\end{array}$ & $\begin{array}{l}0.783 \\
0.713 \\
0.633 \\
\end{array}$ & $\begin{array}{l}1.056 \\
1.018 \\
1.020\end{array}$ \\
\hline
\end{tabular}

Table 5 Comparison of Analytically Calculated Ultimate Strength with Predicted Strength (for various values of $r$ and $\sigma_{y}$ ).

and is also the design formula for the fixed arch.

The accuracy of this formula in predicting the strength of fixed arches is demonstrated in Fig. 10 for a series of arches with $h / L=0.15$ and $\lambda=100,200$ and 300 . The solid curve shows interaction between $\hat{n}$ and $\hat{m}$, and is obtained directly by Eqs. (12.1), (12.2) and (12.3). The circular marks represent the critical combination of $\hat{n}$ and $\hat{m}$ given by Eq. (9) in which $\tilde{f}$ and $\hat{f}$ are determined by the ultimate strength analysis, and $\tilde{n}$ and $\tilde{m}$ are analyzed by the convensional first-order elastic analysis. All the calculations are shown in detail in Table 3, where the ultimate strength predicted by Eqs. (12.1) and (12.2) is compared with the analytically determined ultimate strength, using a correlation factor $F_{c}$. The $F_{c}$ is obtained by solving equations as follows:

$$
\begin{aligned}
& a\left[\frac{\hat{m}}{F_{c}}\right]^{2}+b\left[\frac{\hat{m}}{F_{c}}\right]+c\left[\frac{\hat{n}}{F_{c}}\right]=1 \text { for } \frac{\hat{n}}{F_{c}} \geqq n_{c r} \\
& \alpha\left[\frac{\hat{m}}{F_{c}}\right]+\beta\left[\frac{\hat{n}}{F_{c}}\right]=1 \text { for } \frac{\hat{n}}{F_{c}}<n_{c r}
\end{aligned}
$$

in which $\hat{n}$ and $\hat{m}$ are analytically determined and given by Eq. (9) and the slenderness ratio parameter is difined by Eq. (12.3). Some comparisons for arches with different rise-to-span ratios and yield stresses are shown in Tables 4 and 5, respectively. The correlation factors for the twenty one cases studied are gathering between 0.937 and 1.152 . The average is $1.024(2.4 \%)$. It can therefore be concluded that the proposed formula can provide good estimates of the ultimate strength of fixed arches for use in design.

The final step in the development of the design procedure is to derive a design formula for fixed arches expressed in terms of the axial thrust and bending moment of the replaced arch. When arches are designed by the limit state approach based on the ultimate strength, a design should be considered to be satisfactory if the calculated strength is equal to or greater than the required strength for the factored load. For the fixed arch studied, the calculated strength is $q_{\max }^{f}$, and is equal to $\hat{q}_{\max }$ of the equivalent arch. When the load $q_{\max }^{f}$ is applied to the equivalent arch the axial thrust $\hat{N}$ and bending moment $\hat{M}$ are given by Eq. (5). 
When the same $q_{\max }^{f}$ is applied to the replaced arch, the axial thrust $\bar{N}$ and bending moment $\bar{M}$ are : $\bar{N}=k_{n} q_{\max }^{f} ; \bar{M} / L=k_{m} q_{\max }^{f}$

Combining Eqs. (5) and (14) gives:

$$
\hat{N}=\bar{N} ; \hat{M}=K \bar{M}
$$

Then, Eqs. (12.1) and (12.2) can be rewritten in terms of $\bar{M}$ and $\bar{N}$ as follows:

$$
\begin{aligned}
& a\left[K \frac{\bar{M}}{M_{y}}\right]^{2}+b\left[K \frac{\bar{M}}{M_{y}}\right]+c\left[\frac{\bar{N}}{N_{y}}\right] \leqq 1 \text { for } \frac{\bar{N}}{N_{y}} \geqq n_{c r} \\
& \alpha\left[K \frac{\bar{M}}{M_{y}}\right]+\beta\left[\frac{\bar{N}}{N_{y}}\right] \leqq 1 \text { for } \frac{\bar{N}}{N_{y}}<n_{c r}
\end{aligned}
$$

The equivalent slenderness ratio parameter is given by the general expression, Eq. (12.3), which is repeated here for convenience, namely:

$$
\bar{\lambda}=K \lambda \sqrt{\sigma_{y} / E} / \pi
$$

These equations are, finally, proposed formulas for the fixed arches. In the design process, $\bar{N}$ and $\bar{M}$ are axial thrust and bending moment at the critical quarter point of the replaced hinged arch corresponding to the designed fixed arch. They are determined by the first-order elastic analysis for the factored design load. The loading condition usually involves dead load over the entire span and live load (including impact) over half of the span.

\section{SUMMARY}

The study reported herein was undertaken to develop an ultimate strength design for fixed-end steel arches with thin-walled welded box section. The following conclusions may be reached chiefly:

(1) The ultimate load of the fixed arch is related to that of an equivalent hinged arch using the effective length factor defined by Eq. (2). This relation becomes the key step in establishing the ultimate strength design formulas.

(2) The design criteria proposed previously for hinged arches are then modified to provide the criteria applicable to the equivalent arch given by Eqs. (12.1), (12.2) and (12.3).

(3) It has been shown how the design criterion for a replaced hinged arch can be transformed to become the criterion for the equivalent arch, based on the calculated results of the ultimate loads for the fixed and replaced arches.

(4) Then, a more direct and practical procedure employing a replaced hinged arch in the design calculation has been presented by Eqs. (16.1), (16.2) and (16.3).

In order that a fixed-end steel arch attains the computed ultimate load, its rotation capacity is essential. Particularly, the rotation capacity is required for redistribution of the fixed-end bending moment in inelastic range. Work on development of such required capacity is needed.

\section{ACKNOWLEDGEMENTS}

This paper was drafted at Lehigh University and it was made possible through support of the Exchange Professor Program of the Ministry of Education in Japan awarded to the first writer. The writers wish to thank Messrs. N. Tokashiki and K. Nomura of the Department of Civil Engineering at University of Ryukyu for drawings and some parts of the computer runs. The writers also would like to express their appreciation to Professor S. Vinnakota of the Department of Civil Engineering at Marquette University for making valuable comments, when they were planning this draft.

\section{REFERENCES}

1) Komatsu, S. : Stability and Strength of Braced Steel Arches, Chapter 9 of Steel Framed Structures edited by Narayanan, Elsever Science Publ., London, 1985.

2) Komatsu, S. and Shinke, T. : Practical Formulation for In-Plane Load Carrying Capacity of Arches, Proc. of JSCE, No. 267, pp. 39 52, 1977 (in Japanese). 
3) Yabuki, T., Vinnakota, S. and Kuranishi, S. : Fixed-End Restraint Effect on Steel Arch Strength, Journal of Structural Engineering, Proc. of ASCE, Vol. 112, No.4, pp. 653 664, 1986.

4) Yabuki, T. and Vinnakota, S. : Stability of Steel Arch Bridges, A State-of-the-Art Report, SM Archives, Vol.9, Martinus Nijhoff Publishers, The Hague, The Netherlands, pp. 115 158, 1984.

5) Kuranishi, S. and Yabuki, T. : Ultimate Strength Design Criteria For Tow-Hinged Steel Arch Structures, Proc. of JSCE, Structural Eng. /Earthquake Eng., Vol. 1, No.2, pp. 229 237, 1984.

6) Nishino, F. : Buckling Strength of Columns and Their Component Plates, Fritz Engineering Laboratory Report, No. 290. 10, Lehigh University, 1964.

7) Zienckiewicz, O. C. : The Finite Element Method, 3rd Ed., McGraw-Hill Book Co., Ltd., London, England, 1977.

8) Japan Road Association: Specification for Highway Bridges, 1980 (in Japanese).

9) American Association of State Highway and Transportation Officials : Standard Specifications for Highway Bridges, 13 th edition, 1983. 